\title{
Marked delay in indocyanine green plasma clearance with a near-normal bromosulphophthalein retention test: a constitutional abnormality?
}

\author{
K. OKUDA ${ }^{1}$, H. OHKUBO, H. MUSHA, K. KOTODA, H. ABE, AND \\ K. TANIKAWA \\ From the First Department of Medicine, Chiba University School of Medicine, Chiba, and \\ Second Department of Medicine, Kurume University School of Medicine, Kurume, Japan
}

SUMMARY Five patients showing a normal to near-normal BSP test and a marked delay in ICG plasma clearance, and two families with clustering of the same abnormality, are described. Two had Gilbert's syndrome, one was convalescing from acute hepatitis, and the other two had no detectable liver abnormality. Measured indices of ICG metabolism indicated a marked reduction in the hepatic uptake, storage capacity, biliary transport maximum, and an increased reflux into plasma. Biochemical studies on the binding of ICG by plasma proteins failed to demonstrate any difference from normal controls. Thus, the primary defect seems to be in the transport of ICG by the hepatocyte. Although the relationship of the defect in ICG metabolism to other constitutional hyperbilirubinaemias is not clear, it is possible that the defect in these patients is a constitutional one involving some steps in the hepatic disposal of organic anions.

Indocyanine green (ICG) has supplanted bromosulphophthalein (BSP) as a liver function test mainly because of the occasional severe reactions to the latter. Unlike BSP, ICG is not conjugated in the liver nor reabsorbed from the gut, and serves as a more direct indicator of the excretory capability of hepatocytes (Cherrick et al., 1960; Caesar et al., 1961). During the past few years, we have encountered five patients, two with mild hyperbilirubinaemia and three without, in whom a striking retention of intravenous ICG was noted in the absence of grossly abnormal BSP test. Study of the families of two propositi revealed a high incidence of the same abnormality. A number of similar cases with markedly disparate BSP and ICG tests are being seen in Japan, including several familial occurrences and some with Gilbert's syndrome (Nambu and Namihisa, 1975; Namihisa et al., 1975; Ohkubo et al., 1975). The abnormality is always in the clearance of ICG, while the BSP test is normal or near normal, and there is no liver pathology. Thus, this selective abnormality in ICG metabolism seems to reflect some constitutional defect.

${ }^{1}$ Address for correspondence: Dr Kunio Okuda, Chiba University Hospital, Chiba (280), Japan.

Received for publication 21 April 1976

\section{Patients}

Of the five patients found to have selective ICG abnormality, two (cases 1 and 2) had clinical features of Gilbert's syndrome. Case 3 had a chronic cervical lymphadenitis. Case 4 had an acute, HBsAg negative hepatitis and ICG retention was noted after recovery. Case 5 had a prostate carcinoma, and had been treated with oestrogen (200 $\mathrm{mg} /$ day). Biopsy histology was available in all and was unremarkable. The laboratory data are shown in Table 1.

\section{Methods}

Serum bilirubin was determined by Michaëlsson's modification (1961) of the Jendrassik method, and the direct bilirubin was measured at 15 minutes. BSP and ICG in serum or plasma were determined spectrophotometrically at $594 \mathrm{~nm}$ and $805 \mathrm{~nm}$, respectively. Plasma disappearance curves were drawn after intravenous administration of $0.5 \mathrm{mg} / \mathrm{kg}$ ICG or $5 \mathrm{mg} / \mathrm{kg}$ BSP under fasting conditions. The kinetics of each dye was studied according to the method of Barber-Riley et al. (1961), based on a two compartments model. Data were plotted on a semilogarithmic scale, and ' $a$ ', ' $b$ ', and ' $h$ ' were 
Table 1 Major laboratory tests in five patients with dissociated ICG and BSP tests

\begin{tabular}{|c|c|c|c|c|c|}
\hline \multirow[t]{2}{*}{ Test } & \multicolumn{5}{|l|}{ Case } \\
\hline & $l(22 y r, M)$ & $2(34 y r, M)$ & $3(25 y r, M)$ & $4(35 y r, F)$ & $5(70 y r, M)$ \\
\hline Erythrocyte count $\left(10^{4} / \mathrm{cu} \mathrm{mm}\right)$ & 487 & 510 & 440 & 405 & 375 \\
\hline Haemoglobin (g/dl) & $14 \cdot 4$ & $16 \cdot 0$ & 13.4 & $13 \cdot 0$ & $11 \cdot 0$ \\
\hline Reticulocytes $(\%)$ & 0.6 & $1 \cdot 0$ & 0.6 & 0.5 & $1 \cdot 1$ \\
\hline Serum bilirubin $(\mathrm{mg} / 100 \mathrm{ml})^{*}$ & $2 \cdot 8$ & $3 \cdot 4$ & 0.6 & 0.9 & 0.5 \\
\hline Direct (15 min direct)* & 0.6 & $1 \cdot 2$ & $0 \cdot 1$ & 0.4 & $0 \cdot 1$ \\
\hline SGOT (IU) (normal, 7-40) & 24 & 26 & 29 & 32 & 34 \\
\hline SGPT (IU) (normal, 5-40) & 41 & 19 & 30 & 36 & 23 \\
\hline Alkaline phophatase (Bessey U) (0.9-2.9) & $1 \cdot 9$ & $1 \cdot 0$ & 1.0 & $2 \cdot 3$ & $5 \cdot 9$ \\
\hline Albumin $(\mathrm{g} / 100 \mathrm{ml})$ & $3 \cdot 9$ & $5 \cdot 2$ & $4 \cdot 9$ & $5 \cdot 1$ & $3 \cdot 7$ \\
\hline$\gamma$-globulin $(\mathrm{g} / 100 \mathrm{ml})$ & $1 \cdot 2$ & $1 \cdot 1$ & 0.7 & $1 \cdot 5$ & $1 \cdot 3$ \\
\hline Serum iron $(\mu \mathrm{g} / 100 \mathrm{ml})$ & 85 & 165 & 105 & 120 & 180 \\
\hline Haptoglobin (mg/100 ml) & 195 & 254 & 264 & 205 & 120 \\
\hline Coombs test, direct and indirect & $(-)$ & $(-)$ & $(-)$ & $(-)$ & $(-)$ \\
\hline Hepatitis B surface antigen & $(-)$ & $(-)$ & $(-)$ & $(-)$ & $(-)$ \\
\hline
\end{tabular}

*By Michaëlsson's (1961) modification of Jendrassik method.

calculated from the exponential components of the curve. They represent the fractional transfer rates from plasma to liver, liver to plasma, and liver to bile, respectively. Disappearance rate ' $k$ ' was calculated from $k=\frac{0.693}{t \frac{1}{2}}$, where $t \frac{1}{2}$ is half time of the initial slope. Secretory transport maximum $(T m)$ and relative storage capacity $(S)$ were determined according to the procedure of Wheeler $e t$ al. (1960). ICG, $75 \mathrm{mg}$ in $500 \mathrm{ml} 5 \%$ glucose, was infused at $0.6 \mathrm{mg} / \mathrm{min}, 0.1 \mathrm{mg} / \mathrm{min}$, and $0.3 \mathrm{mg} / \mathrm{min}$; BSP, $900 \mathrm{mg}$ in $500 \mathrm{ml}$ saline, was infused at 6.0 $\mathrm{mg} / \mathrm{min}, 1.0 \mathrm{mg} / \mathrm{min}$, and $3.0 \mathrm{mg} / \mathrm{min}$.

Sephadex G-200 gel filtration and diethylaminoethyl cellulose (DEAE) chromatography (Sober and Peterson, 1958) were carried out to study binding of ICG by serum proteins. One millilitre of serum was filtered through a $16 \times 700 \mathrm{~mm}$ Sephadex column using $0.01 \mathrm{M}$ phosphate buffer of $\mathrm{pH} 7.4$ in $0.5 \mathrm{M}$ $\mathrm{NaCl}$ at a speed of $5 \mathrm{ml} / \mathrm{h}$; DEAE chromatography was carried out using a $10 \times 100 \mathrm{~mm}$ column and

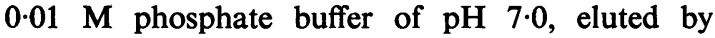
changing the phosphate buffer to $0.05 \mathrm{M}, 0.10 \mathrm{M}$, $0.15 \mathrm{M}, 0.20 \mathrm{M}, 0.25 \mathrm{M}$, and $0.3 \mathrm{M} \mathrm{NaCl}$, and finally to $0.5 \mathrm{M} \mathrm{NaOH}$.

Bilirubin load test was that of Billing et al. (1964). From the clearance curve, transfer rates ' $a$ ', ' $b$ ', and ' $m$ ', were calculated; where ' $a$ ' is the rate of uptake of bilirubin by the liver, ' $b$ ' rate at which unconjugated bilirubin is being returned to plasma, and ' $m$ ' rate of transfer of unconjugated bilirubin in the liver to the conjugated biliru'sin compartment.

\section{Results}

PLASMA DISAPPEARANCE CURVES FOR ICG AND BSP

Attempts were made to determine $a, b$ and $h$ for
ICG and BSP. In case 1, in which $\mathrm{k}$ for ICG was extremely low $(0.022)$ and 15 minute retention (R $\mathbf{R}_{15 . I C G)}$ 67.3\%, plasma ICG declined linearly and calculation of $a, b$ and $h$ was impossible. R45.BSP was $4.9 \%$ and only minimally delayed (Fig. 1; Table 2 ). Very similar results were obtained for ICG in case 2. The $\mathbf{k}$ for BSP was 0.041, smaller than normal, and an abnormality in the initial decline was suggested as described by Berk et al. (1972). In case 3, $\mathrm{k}$ for ICG was even smaller, and a deviation (step) from the initial decline curve (Namihisa et al., 1974) was noted, making the calculation of $a, b$,

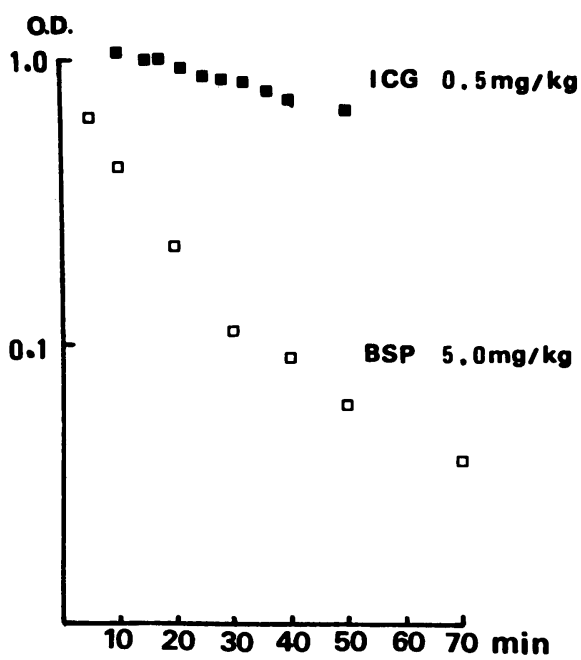

Fig. 1 Plasma disappearance curves for ICG and BSP in case 1. Retention of BSP at 45 min was $4.9 \%$, and of ICG at $15 \mathrm{~min}, 67 \cdot 3 \%$. Calculation of transfer rates $\mathrm{a}, \mathrm{b}$, and $\mathrm{h}$ was not possible because of the linear decay of plasma ICG. 
Table 2 Plasma disappearance rate $(K)$, retention rate $(R)$, and transfer rate constants $(\mathrm{a}, \mathrm{b}, \mathrm{h})$ for $I C G$ and $B S P$ in five patients

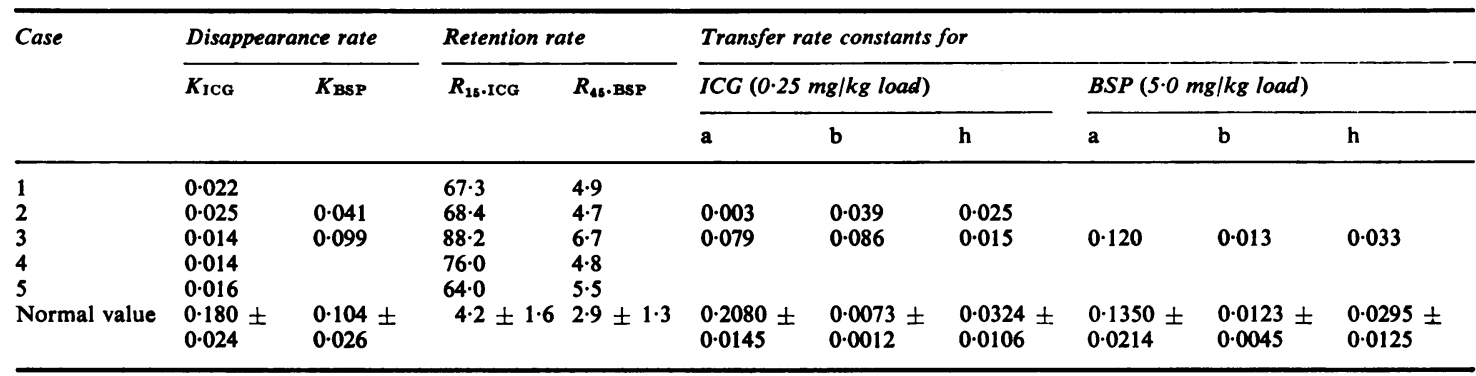

Normal values are based on the data in our laboratory. Figures are mean \pm standard deviation.

and $h$ impossible. The $\mathrm{k}$ for BSP was 0.099 and nearly normal.

When ICG load was reduced to $0.25 \mathrm{mg} / \mathrm{kg}$, a change in the slope of plasma disappearance curve occurred around 20 minutes. The calculated values of $a, b$, and $h$ for case 2 were $0.033,0.039$, and 0.025 , and for case $3,0.079,0.086$, and 0.015 respectively (Table 2). In both, $a$ was extremely small, $b$ greater than normal, and $h$ decreased mildly.

The Tm and $S$ for cases 1-3 (Table 3) indicated marked reduction of both for ICG; reduction of $S$ was particularly pronounced in the two cases with unconjugated hyperbilirubinaemia. The $T m$ for BSP was relatively low in cases 1 and 2, but control values varied considerably and the degree of reduction was smaller compared with that for ICG.

BINDING OF ICG BY PLASMA PROTEINS

One millilitre serum containing $0.2 \mathrm{mg}$ ICG was applied on a Sephadex column. Most ICG was bound to protein peaks I and II (Flodin and Killander, 1962) (Fig. 2), and there was no significant difference between patients and six normal subjects in the relative ICG content in each protein fraction. Stepwise DEAE chromatography was also carried out for the same material. The bulk of ICG was eluted at 0.2-0.3 $\mathrm{M} \mathrm{NaCl}$ (Fig. 3), and no difference was noted between the patient and control. Sera obtained at five, 10 and 15 minutes after intravenous injection of $0.5 \mathrm{mg} / \mathrm{kg}$ ICG, were then applied on Sephadex columns. Peaks I and II contained more than $70 \%$ of the ICG in serum and, although ICG concentration decreased with time, the relative proportion in each peak remained rather constant. No difference was noted in ICG distribution nor in its amount bound per unit protein between the patient and control regardless of time.

\section{BILIRUBIN LOAD TEST}

Test was given in three patients. In case $1, a$ was $0.0046, b 0.0047$, and $m 0.007$, and in case $2, a$ $0.0125, b 0.0072$, and $m 0.0052$, all being markedly reduced as reported by Billing et al. (1964) in Gilbert's syndrome. In case $3, a$ was $0.018, b 0.014$, and $m 0.0038$, with a mild reduction in $a$.

\section{FAMILY STUDY}

We were able to study two families. In the family of case 4, an older sister showed $R_{15 . I C G}$ of $67.5 \%$, and $\mathbf{R}_{45 . B S P} 4.5 \%$; a 26 year old brother showed $\mathbf{R}_{15 . \text { ICG }}$ of $85.0 \%$ and $R_{45 . B S P} 7.2 \%$. Mother and a younger sister had mildly abnormal ICG tests, and only one sister was normal in the dye study (Fig. 4, above). None had any indication of liver disease. In the family of case 5 , three of five of his live children had abnormal ICG retention without abnormal

Table 3 Secretory transport maximum (Tm) and relative storage capacity (S) for ICG and BSP in three patients

\begin{tabular}{|c|c|c|c|c|}
\hline \multirow[t]{2}{*}{ Case } & \multicolumn{2}{|l|}{$I C G$} & \multicolumn{2}{|l|}{$B S P$} \\
\hline & $T m(m g / m i n)$ & $S(m g / m g \%)$ & $T m(m g / m i n)$ & $S(m g / m g \%)$ \\
\hline
\end{tabular}

* Data in our laboratory.

Figures are mean \pm SD. 

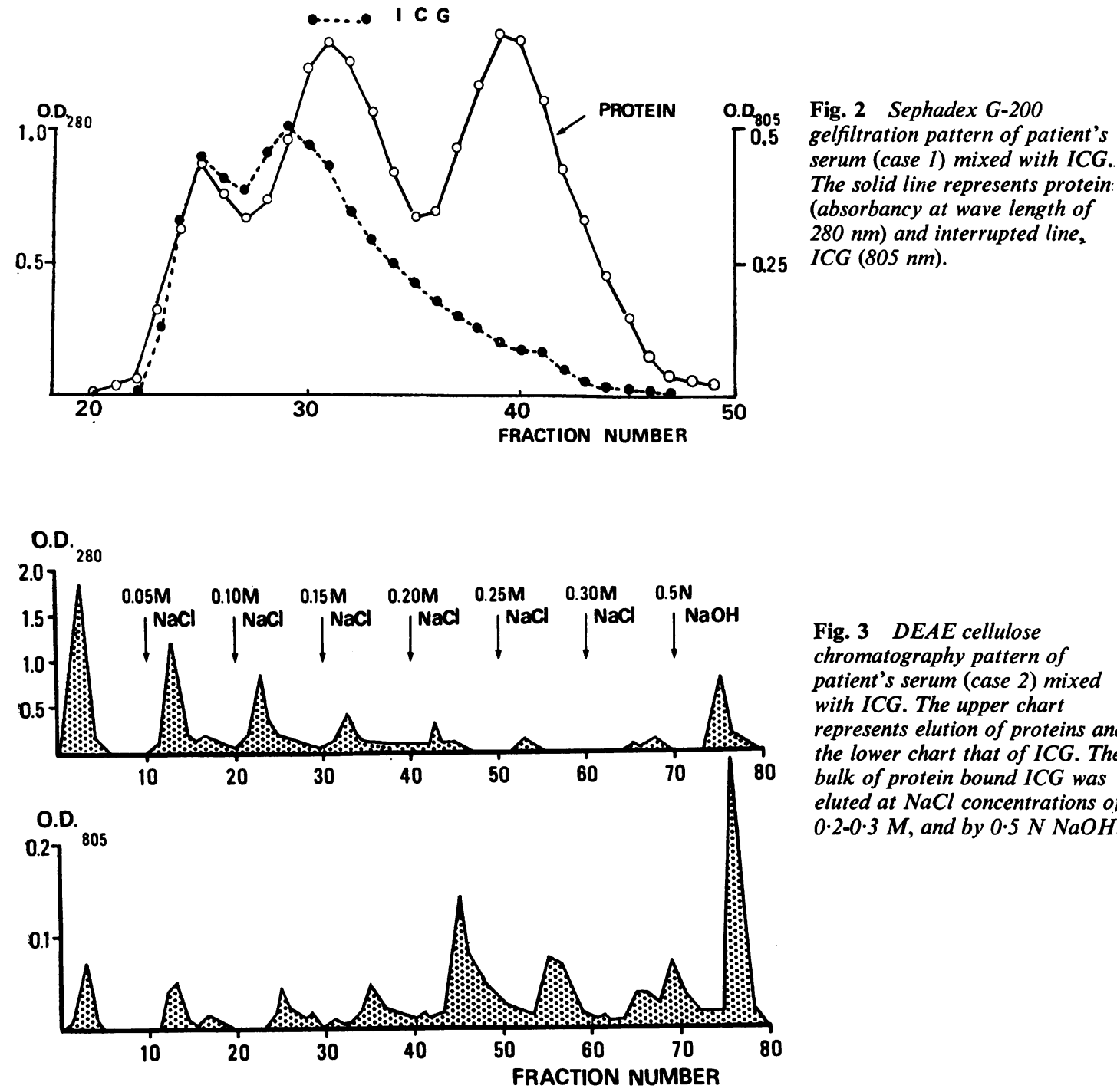

Fig. 3 DEAE cellulose chromatography pattern of patient's serum (case 2) mixed with ICG. The upper chart represents elution of proteins and the lower chart that of ICG. The bulk of protein bound ICG was eluted at $\mathrm{NaCl}$ concentrations of $0 \cdot 2-0 \cdot 3 \mathrm{M}$, and by $0.5 \mathrm{~N} \mathrm{NaOH}$.

chemistry (Fig. 4, below). No consanguinity was demonstrated in these families and pedigrees. Presuming that this defective ICG metabolism is transmitted, the mode of inheritance is compatible with being autosomal recessive or incomplete dominant.

\section{INCIDENCE OF SELECTIVE ABNORMALITY OF} ICG METABOLISM

Three cases were seen at the Liver Unit, Chiba University Hospital, where ICG test has been used in preference to BSP for the past five years. Since the beginning of 1973, patients exhibiting abnormal
ICG retention have been studied in comparison with BSP. In 1973 and 1974, 1259 patients, including eight with constitutional unconjugated hyperbilirubinaemia, had ICG tests. Approximately one-fifth showed a definite ICG retention because of overt liver involvement, masking any selective abnormality. By subtracting them from the total, the incidence of disparity between marked ICG retention and normal BSP test has been calculated as roughly three out of 1000 , and two out of eight with Gilbert's syndrome. These figures are by no means accurate, but do indicate that this abnormality is more frequent in Gilbert's syndrome. There has been no 

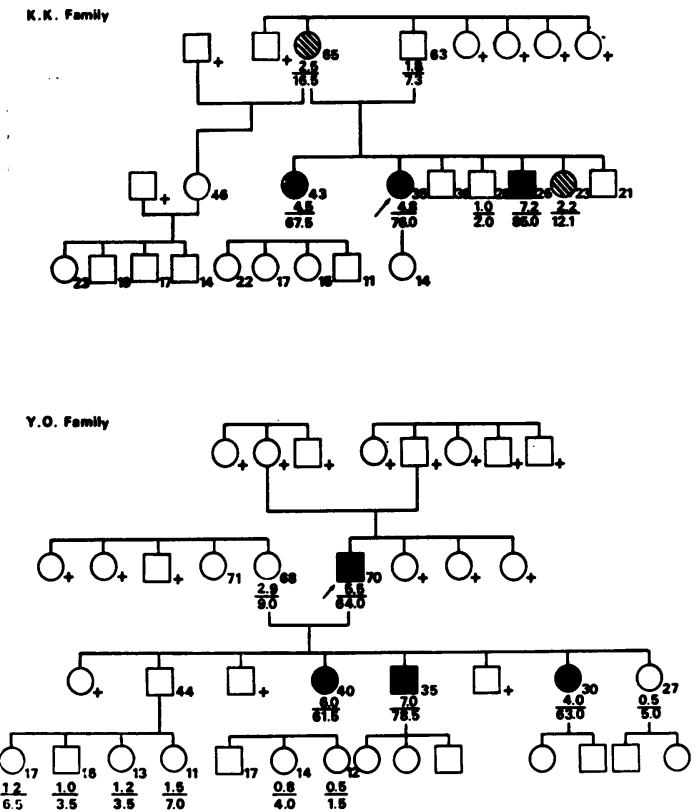

Fig. 4 Pedigree of the families studied. The squares represent males, the circles, females, the crosses, deceased. The numbers below the squares and circles to the right indicate the ages, and the fractional numbers, $\boldsymbol{R}_{45}$. BSP over $\boldsymbol{R}_{15}$.ICG in per cent.

selective BSP abnormality in the face of normal ICG test in approximately $200 \mathrm{BSP}$ tests done during this period.

\section{Discussion}

Although the $\mathrm{k}$ value obtained with the recommended dose of $0.5 \mathrm{mg} / \mathrm{kg} \mathrm{ICG}$ is greater than that for $5 \mathrm{mg} / \mathrm{kg} \mathrm{BSP}$, it has been established that there is good correlation between the two tests (Cherrick et al., 1960; Hunton et al., 1960; Caesar et al., 1961; Leevy, 1961). The Japanese Society of Gastroenterology made a recommendation in 1969 to determine the 15 minute retention using the same dose. Thus, $R_{15 . I C G}$ is a few per cent higher than $\mathbf{R}_{45 . B S P}$ (Kinjo, 1973). In most cases with mild disparate dye retentions due to hepatic dysfunction, ICG fails to detect abnormality while plasma BSP clearance is delayed. In cirrhosis, $R_{45 . B S P}$ is deceptive because of the low initial plasma level due to expanded plasma volume (Mendenhall and Leevy, 1961). Patients with a striking ICG retention and a normal to near-normal BSP test have not been particularly noted in the occidental literature. Up to the end of 1974, nearly 30 cases were reported in Japan including six cases of mild unconjugated hyperbilirubinaemia and several familial occurrences (Namihisa et al., 1973; Namihisa et al., 1974; Kuchiba and Kondo, 1974; Nambu and Namihisa, 1975; Ohkubo et al., 1975). It is not clear whether it is due to an ethnic difference or to the popularity of the ICG test in Japan. Because of the absence of abnormality in liver function and histology, these cases are most probably the result of a constitutional defect in the hepatic excretion of ICG. From work based on a family study, Kuchiba and Kondo (1974) suggested that the defect is transmitted by an autosomal recessive mode.

The measured transfer rates and relative storage capacity suggest that the basic defect in these patients resided in the hepatic uptake of ICG with a reduced retaining capacity. Namihisa et al. (1973) observed in their patients a step-like change in the disappearance curves for ICG and BSP around 20 minutes from injection, and thought it to be pathognomonic. In one of our patients a similar step was noted. Impaired hepatic uptake may be accounted for by (1) abnormality in binding of ICG by serum proteins, (2) morphological and functional disturbances of the hepatic cell membrane, or (3) reduced capacity of intracellular transport. The results of early investigations on ICG conjugation by serum proteins were inconsistent, probably because of the different techniques (Cherrick et al., 1960; Baker, 1966) and ICG doses (Janecki and Krawcynski, 1970). The results of our study were in accord with those of Kamisaka et al. (1974) who demonstrated the 19s fraction to be the primary binder at low ICG concentrations. According to Kawasaki et al. (1973), the proportion of ICG bound to albumin was greater in patients with selective ICG-excretion abnormality as analysed with Sephadex G-200, but our study failed to show any difference.

The intracellular transport of most organic anions is effected by carrier proteins $\mathrm{Y}$ and $\mathrm{Z}$ (Levi et al., 1969) which, in our cases, do not seem to be the major factor as BSP study demonstrated near normal excretion. The Tm for BSP was somewhat low in cases 1 and 2 but the reduction relative to a wide range of normal values was small enough to account for their $\mathbf{R}_{45}$. BSP. It has not been settled whether the major abnormality in Gilbert's syndrome is in hepatic bilirubin uptake (Schmid and Hammaker, 1959; Billing et al., 1964) or bilirubin conjugation (Arias et al., 1969; Black and Billing, 1969). From their observation of abnormal BSP metabolism in nine out of 26 cases of Gilbert's syndrome, Berk et al. (1972) suggested heterogeneity of the population classified under this diagnosis and involvement of organic anion other than bilirubin. They found no abnormality of ICG metabolism in their 26 Gilbert patients. Abnormal ICG excretion 
has been more frequent among patients with constitutional unconjugated hyperbilirubinaemia in our series as well as in the collected cases in Japan. It is possible, but remains to be proven, that Gilbert's syndrome diagnosed with the current criteria encompasses more than one metabolic defect, and that there are patients who share a common defect in ICG handling with those exhibiting abnormality in ICG in the absence of overt jaundice. It has been shown that bilirubin conjugates are excreted into bile through a pathway which differs from that for bile salt (Alpert et al., 1969). There may be many steps in the hepatic transport and biliary excretion of organic anions that have not been elucidated; bilirubin, ICG and BSP share some but not all of them for their excretion. Another line of explanation is that our two patients with Gilbert's syndrome represent a hitherto unrecognized constitutional abnormality characterised by a igrossly defective hepatic handling of ICG and bilirubin with near normal BSP metabolism. The argument that these cases represent an extreme variance within the normal quantitative relationship among the three organic anions may be refuted by the established close correlation between BSP and ICG tests, by the failure of Berk et al. (1972) to find abnormal ICG test in 26 Gilbert patients, and by the failure of 20 liver units in Japan which have reported this selective ICG defect, to find a single case of selective BSP handling defect with normal ICG test and normal liver histology (Nambu and Namihisa, 1975).

\section{References}

Alpert, S, Mosher, M., Shanske, A., and Arias, I. M. (1969). Multiplicity of hepatic excretory mechanisms for organic anions. Journal of General Physiology, 53, 238-247.

Arias, I. M., Gartner, L. M., Cohen, M., Ben Ezzer, J., and Levi, A. J. (1969). Chronic nonhemolytic unconjugated hyperbilirubinemia with glucuronyl transferase deficiency. American Journal of Medicine, 47, 395-409.

Baker, K. J. (1966). Binding of sulfobromophthalein (BSP) sodium and indocyanine green (ICG) by plasma $a_{1}$ lipoprotein. Proceedings of the Society for Experimental Biology and Medicine, 122, 957-963.

Barber-Riley, G., Goetzee, A. E., Richards, T. G., and Thomson, J. Y. (1961). The transfer of bromsulphthalein from the plasma to the bile in man. Clinical Science, 20, 149-159.

Berk, P. D., Blaschke, T. F., and Waggoner, J. G. (1972). Defective bromosulfophthalein clearance in patients with constitutional hepatic dysfunction (Gilbert's syndrome). Gastroenterology, 63, 472-481.

Billing, B. H., Williams, R., and Richards, T. G. (1964). Defects in hepatic transport of bilirubin in congenital hyperbilirubinaemia: an analysis of plasma bilirubin disappearance curves. Clinical Science, 27, 245-257.

Black, M., and Billing, B. H. (1969). Hepatic bilirubin UDPglucuronyl transferase activity in liver disease and Gilbert's syndrome. New England Journal of Medicine, 280, 12661271.

Caesar, J., Shaldon, S., Chiandussi, L., Guevara, L., and
Sherlock, S. (1961). The use of indocyanine green in the measurement of hepatic blood flow and as a test of hepatic function. Clinical Science, 21, 43-57.

Cherrick, G. R., Stein, S. W., Leevy, C. M., and Davidson, C. S. (1960). Indocyanine green: observations on its physical properties, plasma decay, and hepatic extraction. Journal of Clinica' Investigation, 39, 592-600.

Flodin, P., and Killander, J. (1962). Fractionation of human-serum proteins by gel filtration. Biochimica et Biophysica Acta, 63, 403-410.

Hunton, D. B., Bollman, J. L., and Hoffman, H. N. (1960). Studies on hepatic function with indocyanine green. Gastroenterology, 39, 713-724.

Janecki, J., and Krawcynski, J. (1970). Labelling with indocyanine green of serum protein from normal persons and patients with acute viral hepatitis. Clinica Chemica Acta, 16, 1008-1011.

Japanese Society of Gastroenterology (1969). Standardization of indocyanine green test-report of the Committee on the Liver Function Tests. Japanese Journal of Gastroenterology, 66, 151-152. (In Japanese.)

Kamisaka, K., Yatsuji, Y., Yamada, H., and Kameda, H. (1974). The binding of indocyanine green and other organic anions to serum proteins in liver diseases. Clinica Chimica Acta, 53, 255-264.

Kawasaki, H., Oma, H., Sakaguchi, S., Tominaga, K., and Hirayama, C. (1973). Abnormal binding of indocyanine green with serum proteins in a patient with delayed ICG clearance. Clinica Chimica Acta, 47, 39-43.

Kinjo, K. (1973). Study of the differences between bromosulfalein (BSP) and indocyanine green (ICG) tests. Japanese Journal of Gastroenterology, 70, 643-657. (In Japanese.)

Kuchiba, K., and Kondo, R. (1974). Studies on familially observed delay in clearance of plasma indocyanine green. Acta Hepatologica Japonica, 17, 223-227.

Leevy, C. M. (1961). Dye excretion by the liver. In Progress in Liver Diseases, vol. 1, pp. 174-186. Edited by H. Popper and F. Schaffner. Grune and Stratton: New York.

Levi, A. J., Gatmaitan, Z., and Arias, I. M. (1969). Two hepatic cytoplasmic protein fractions, $Y$ and $Z$, and their possible role in the hepatic uptake of bilirubin, sulfobromophthalein, and other anions. Journal of Clinical Investigation, 48, 2156-2167.

Mendenhall, C. L., and Leevy, C. M. (1961). False-negative bromsulfalein tests. New England Journal of Medicine, 264, 431-433.

Michaëlsson, M. (1961). Bilirubin determination in serum and urine. Scandinavian Journal of Clinical and Laboratory Investigation, 13, suppl. 56,

Nambu, M., and Namihisa, T. (1975). Constitutional ICG excretory defect-investigation of cases reported until December, 1974. Japanese Journal of Gastroenterology, 72, 1002-1014. (In Japanese.)

Namihisa, T., Nambu, M., Kobayashi, N., and Kuroda, $\mathbf{H}$. (1974). A case with apparent discrepancy between ICG test and BSP test. (Constitutional ICG excretory defect.) Characteristic change on plasma disappearance curve. Japanese Journal of Gastroenterology, 71, 168-173. (In Japanese.)

Namihisa, T., Nambu, M., Kobayashi, H., Kuroda, H., and Hisauchi, T. (1973). Hepatic transport of indocyanine green and bromsulphalein in two cases with discrepancy. Japanese Journal of Gastroenterology, 70, 966-976. (In Japanese.)

Namihisa, T., Nambu, M., Kobayashi, N., and Yamashiro, $Y$. (1975). Hepatic dye transport in constitutional hyperbilirubinemia and constitutional ICG excretory defect. Act a Hepatologica Japonica, 16, 25-35. (In Japanese.)

Ohkubo, H., Musha, H., Kotoda, K., and Okuda, K. (1975). 
Comparative studies on defective indocyanine green excretion by the liver in patients with and without Gilbert's disease. Japanese Journal of Gastroenterology, 72, 992-1002. (In Japanese.)

Schmid, R., and Hammaker, L. (1959). Glucuronide formation in patients with constitutional hepatic dysfunction (Gilbert's disease). New England Journal of Medicine, 260, 1310-1314.
Sober, H. A., and Peterson, E. A. (1958). Protein chromatography on ion exchange cellulose. Federation Proceedings, 17, 1116-1126.

Wheeler, H. O., Meltzer, J. I., and Bradley, S. E. (1960). Biliary transport and hepatic storage of sulfobromophthalein sodium in the unanesthetized dog, in normal man, and in patients with hepatic disease. Journal of Clinical Investigation, 39, 1131-1144. 